\title{
TOPOGRAFÍAS RELIGIOSAS. LA DIMENSIÓN TERRITORIAL DE LA RELIGIOSIDAD
POPULAR EN EL SIGLO XVIII
}

\author{
María José Ortega Chinchilla \\ Centro de História de Além-Mar \\ Faculdade Ciências Sociais e Humanas \\ Universidade Nova de Lisboa
}

Fecha de recepción: diciembre 2012

Fecha de aceptación: mayo 2013

\section{INTRODUCCIÓN}

Una de las estrategias que emplea el historiador para encarar el binomio espaciosacralización con el fin de contrarrestar el vértigo que producen estos conceptos -por su grado de abstracción y complejidad-, es descender a la escala de lo tangible, a los elementos contables o unidades visibles que pueden identificarse, cuantificarse y ubicarse. De este modo, un método habitual de trabajo lo constituirá la búsqueda de cualquier rastro de lo sagrado en un espacio perfectamente acotado la inspección de sus rincones con el fin de encontrar esa capilla, oratorio, ermita, santuario, cruz callejera, hornacina o imagen que nos ilustre sobre un fenómeno de propaganda religiosa, aculturación, manifestación de la religiosidad popular, exaltación de la fe cristiana, etc. Esta pesquisa se completará con la identificación, descripción y clasificación de dichos testimonios religiosos dentro de una tipología, así como con un estudio de su evolución histórica. Para dicha labor se dejarán asistir por un variado elenco de fuentes documentales que les permita seguir la pista de aquellos elementos de arquitectura menor que se dice se erigieron en tal esquina, calle, plaza o paraje donde continúan como documentos vivos, o que por el contrario, desaparecieron para siempre dejándonos como legado tan sólo unos despojos de mampostería, un hueco en la pared, el nombre de una vía o una escueta referencia en un viejo documento.

Los dibujos incluidos entre el vasto conjunto documental del Catastro de Ensenada y los croquis del llamado Diccionario Geográfico de Tomás López han servido en 
algún que otro trabajo para este fin ${ }^{1}$. En esos casos las imágenes fueron utilizadas como testimonios fidedignos de la realidad física, como pistas para la localización e identificación de determinados elementos de arquitectura religiosa menor. El proceso sería el siguiente: el historiador traslada la información visual que les proporcionan las representaciones al campo de trabajo; seguidamente observa y compara, reconoce, comprueba e identifica sobre el terreno aquello de lo que da noticia el documento. Efectivamente, es este un método de trabajo válido para un determinado tipo de investigaciones, pero, obviamente, no el único.

Si nos quedamos en la tradicional concepción de los instrumentos cartográficos como meros espejos de la realidad estaremos mutilando gran parte de su valor informativo $^{2}$. Cierto es que los mapas o planos que vamos a analizar - los croquis remitidos al geógrafo Tomás López y los dibujos insertos en el Catastro de Ensenada- no se corresponden con el tipo de documentos que suelen manejar los historiadores de la cartografía. No obstante, a pesar de sus particularidades, puesto que tratan de plasmar de alguna forma la configuración del espacio geográfico, pretendemos exigirles, igual que a aquellos, un mínimo de correspondencia con la realidad. Pero aunque lo tienen, no es ahí únicamente, ni siquiera principalmente, donde radica su interés.

Por tanto, en lugar de identificar, ubicar y describir de forma pormenorizada diferentes hitos, vestigios o manifestaciones de la religiosidad popular de la España del siglo XVIII utilizando como fuente dichos documentos gráficos, elijo desplazar el foco de atención para fijarlo, más que en estas manifestaciones materiales, en sus observadores. Los interrogantes y sus correspondientes respuestas irán dirigidos a arrojar algo de luz sobre el controvertido tema de las percepciones del entorno vivido. Para ello, en lugar de utilizar estas imágenes como documentos de contraste con la realidad, prefiero trabajarlas desde su interpretación como objetos culturales. Como testimonios de un determinado discurso sobre la concepción del territorio local.

1. Un buen ejemplo de esta metodología de trabajo, minuciosa y erudita, es el trabajo realizado hace ya más de dos décadas y a propósito de la sacralización del espacio en la costa granadina por LóPEz GUADALUPE MuÑoz, Miguel Luis: «Ermitas y oratorios en las vicarías de la costa granadina a comienzos del siglo XIX», Anuario de estudios de la costa granadina, $\mathrm{n}^{\circ}$ 3, 1991. El autor acudió a los dibujos del Catastro de Ensenada y del Diccionario Geográfico de Tomás López para inventariar y ubicar el conjunto de ermitas y oratorios en los territorios de las vicarías de Almuñécar, Salobreña, Motril y Berja en la primera mitad del siglo XIX. En esta misma línea nos encontramos también con el estudio de SEGURA GraíÑo, Cristina y Romero, Juan Ramón: «El Diccionario Geográfico de Tomás López: una fuente para el estudio de la espiritualidad popular. Santuarios y ermitas en las provincias de Córdoba, Sevilla y Huelva en el siglo XVIII», Álvarez Santaló, Carlos, Buxó i Rey, María Jesús y Rodríguez Becerra, Salvador (coords.): La religiosidad popular: antropología e historia, volumen I, Barcelona, 1989, pp. 324-347. Otra obra, ésta más reciente, que merece la pena citar es la de Olmedo SÁnchez, Yolanda: Manifestaciones artísticas de la religiosidad popular en la Granada moderna. Estudio de la arquitectura religiosa menor y de otros espacios de devoción. Granada, 2002.

2. En varios de los capítulos recogidos en el libro póstumo de HARLEY, John Brian: La nueva naturaleza de los mapas, ensayos sobre la historia de la cartografia, México, 2001, el autor realiza una crítica feroz a esta tradicional concepción de los mapas, instrumentos que para él suponen sistemas de códigos totalmente subjetivos. 
Este modo de proceder dará como resultado no un estudio histórico-artístico de las iglesias, ermitas, santuarios o calvarios diseminados en el ámbito rural andaluz del siglo XVIII, sino que nos proporcionará la panorámica sobre un territorio que se percibe como algo más que un espacio económico o político-administrativo por parte de los grupos que lo habitan. Nos aproximará a la compleja cuestión de la dimensión territorial de la religiosidad popular, al tiempo que nos permitirá reflexionar acerca de las construcciones simbólicas y apropiaciones ideológicas del territorio. En definitiva, esta metodología de trabajo y estas fuentes nos presentan la oportunidad de adentrarnos en el sugerente universo de las geografías simbólicas que cargan de contenido los espacios humanos.

\section{PERCEPCIONES EN COLOR SEPIA}

\subsection{Un borrón del terreno}

Fue una escueta nota añadida por el geógrafo Tomás López de Vargas y Machuca ${ }^{3}$ (1731-1802) al final de un escrupuloso interrogatorio compuesto por 15 cuestiones la responsable de que hoy podamos disponer de este material gráfico:

Procurarán los señores formar unas especies de mapas o planos de sus respectivos territorios, de dos o tres leguas en contorno de su pueblo, donde pondrán las ciudades, villas, lugares, aldeas, granjas, caserías, ermitas, ventas, molinos, despoblados, ríos, arroyos, sierras, montes, bosques, caminos, etc. que aunque no esté hecho como de mano de un profesor, nos contentamos con sólo una idea o borrón del terreno, porque la arreglaremos dándole la última mano. Nos consta que muchos son aficionados a geografía y cada uno de estos puede demostrar muy bien lo que hay al contorno ${ }^{4}$.

Esta nota viene a soportar otra responsabilidad adicional: entraña una prueba más del método de trabajo seguido por Tomás López; método que le ha llevado a ser considerado -y dependiendo del tono, descalificado- como geógrafo de gabinete. Efectivamente, López trabaja con fuentes impresas, eludiendo el trabajo de campo. Pesó mucho a este respecto su experiencia formativa junto al que fue uno de sus maestros durante los años que estuvo becado en París (1752-1760), el geógrafo francés D'Anvilles.

3. Una de las obras más recientes sobre el geógrafo Tomás López y su producción cartográfica es la publicada por López Gómez, Antonio y Manso Porto, Carmen: Cartografia del siglo XVIII: Tomás López en la Real Academia de la Historia, Madrid, 2006. Sin olvidar la publicada unos años antes por LíTER MAYAYO, Carmen: La obra de Tomás López: imagen cartográfica del siglo XVIII, Madrid, 2002.

4. Dicho interrogatorio y la carta que lo acompaña ha sido publicado en diversas obras, como la de SEGURA Graíño, Cristina y De Miguel, Juan Carlos (eds.): Diccionario Geográfico de Andalucía: Granada, Granada, 1990, pp. 4-5.

5. Este cartógrafo francés junto al que fue su maestro, F. Chevalier, creó, de hecho, una escuela de geógrafos de gabinete. Para profundizar en este tema véase el trabajo de SAN-ANTONIO-Gómez, Carlos de, Manzano Agugliaro, Francisco y León Casas, Miguel Ángel: «Tomás López un cartógrafo de gabinete del siglo XVIII: fuentes y método de trabajo», XVII Congreso Internacional INGEGRAF-ADM., Sevilla, 2005, pp. 1-10. 
Las labores de compilación de fuentes cartográficas de distinta índole, su consulta y contraste con las informaciones directas obtenidas mediante el recurso epistolar, así como una indiscutible intuición, le bastaron para dibujar, grabar y estampar una notable cantidad de mapas sobre los distintos reinos, provincias y ciudades españolas -tampoco faltaron los territorios europeos y americanos- sin la necesidad de realizar una sola operación astronómica ni topográfica conducente a la ejecución de un levantamiento cartográfico. Cuánto se diferenciaba este método de trabajo, por ejemplo, del de su riguroso contemporáneo Cavanilles (1745-1804). Esta oposición se resuelve de forma concisa enfrentando las encuestas por escrito y los croquis de gabinete del primero con las encuestas vivas, las panorámicas y croquis sobre el terreno que efectúa el segundo ${ }^{6}$.

Tomás López, sin embargo, no siente ningún pudor en reconocer y defender su forma de trabajar. Es más, considera este procedimiento como el único viable para un geógrafo. En el segundo tomo de su obra Principios geográficos aplicados al uso de los mapas (1783) afirmará a este respecto lo siguiente:

Dicen bien, que el mejor modo de hacer un mapa es andando y midiendo la tierra, pero este método no es adaptable a las facultades de un particular. El geógrafo trabaja en su casa, teniendo a la vista papeles varios de un mismo terreno, que compara y adapta lo que según su buena crítica es más perfecto. No es ministerio suyo levantar planos particulares, porque para esto hay otra clase de gentes que no necesita mayor instrucción que la de llegar a saber la Geometría Rectilínea. Si los geógrafos necesitaran ver y medir la tierra que comprehenden sus mapas, ninguno hubiera podido durante su vida publicar una de las cuatro partes de la tierra, y es así que hacen las cuatro ${ }^{7}$.

Así es como, sin ver ni medir, su producción cartográfica, desarrollada a lo largo de toda la segunda mitad del siglo XVIII, abarca prácticamente las cuatro partes del globo terráqueo. Según los datos aportados por Líter Mayayo, se contabilizan más de doscientos mapas en hoja suelta y cerca de cuatrocientos si se tienen en cuenta los contenidos en libros y atlas ${ }^{8}$.

Justifica la reunión de mapas impresos y la recopilación de noticias, informes de funcionarios, memorias de particulares, relaciones elaboradas por los encuestados, relatos de viajes, etc., para la buena ejecución de las obras cartográficas argumentando que las observaciones astronómicas no son suficientes para la composición de un mapa pues «el error más pequeño en una observación celeste es de grande consideración en la determinación del punto terrestre correspondiente». De ahí que sea menester «acompañarlas con los itinerarios y relaciones de los mejores viajantes y documentos particulares al asunto del mapa» ${ }^{9}$.

6. LóPez Gómez, Antonio: «Los croquis y mapas del Reino de Valencia de López y Cavanilles: dos geógrafos y dos métodos opuestos», Cuadernos de Geografía, nº 62, 1997, pp. 537-586.

7. López, Tomás: Principios geográficos aplicados al uso de los mapas, Tomo II, Madrid, 1783, pp.147-148.

8. Líter Mayayo, Carmen: La obra de Tomás López..., op. cit., p. 12.

9. LóPez, Tomás: Principios geográficos..., op. cit., p. 144. 
Tiene meridianamente clara, sin embargo, la necesidad de someter a crítica el elenco documental utilizado, especialmente las «noticias y memorias siniestras que suministran aún a los mejores geógrafos»:

No debe evitar el geógrafo el examen de los originales, la lectura de los maestros de la geografía antigua, los viajeros ¡así estos se detuvieran más en las noticias geográficas! pues muchas veces emborronan papel con algunas historias o acontecimientos particulares bastante inoportunos ${ }^{10}$.

Nuestro geógrafo usó, pues, a lo largo de su carrera las respuestas de las gentes particulares, autoridades civiles y eclesiásticas. Carmen Manso apunta la hipótesis de que la primera carta circular que Tomás López envió a los obispos y curas párrocos data del año 1763. Se trata de un primer modelo en el que aún no incluye el interrogatorio y que empleará durante la década de los 60 y hasta 1775. Las respuestas o memorias que les remiten serán empleadas para corregir los mapas ya elaborados o ampliar la información geográfica. Se trata de un grupo de respuestas muy homogéneas acompañadas de sencillos croquis que luego serán reelaborados por el geógrafo. Este modelo de carta que hace circular entre los curas de las distintas localidades de la geografía española y en algunas ocasiones entre las autoridades civiles -como la enviada a los alcaldes de las poblaciones del Reino de Valencia en 1774- será empleado por López con ligeras variantes durante el resto de la década de los 70 y mediados de la siguiente. No será hasta 1784 cuando comience a circular el segundo modelo de carta elaborado por Tomás López junto al interrogatorio ${ }^{11}$. De modo que los croquis que nos encontramos en este trabajo así como las relaciones histórico-geográficas datan de las dos últimas décadas del siglo XVIII.

No era este un proceder nuevo. Todos conocemos el antecedente de las relaciones topográficas de Felipe II de cuya existencia también sabía Tomás López por la copia existente en la Real Academia de la Historia. Tampoco era nueva la petición de dibujos o croquis. Una vez más hemos de hablar aquí de la influencia de la escuela francesa. Como discípulo de D’Anville, que a su vez lo fue de F. Chevalier, Tomás López debió conocer el método de topografía eclesiástica ideado por este último. Se trataba de un procedimiento según el cual los párrocos debían elaborar unos croquis de sus núcleos de población para ser enviados a los cartógrafos de gabinete. El método imponía una normalización mediante plantillas o «châssis orenté»-orientadas en función de la declinación solar- que servirían para unificar los criterios y la simbología de los croquis $^{12}$.

Los croquis enviados a Tomás López fueron realizados, no obstante, sin contar con ningún modelo ni plantilla, de ahí su heterogeneidad. Su falta de precisión y su

10. López, Tomás: Principios geográficos..., op. cit., prólogo p. IV.

11. López Gómez, Antonio y Manso Porto, Carmen: Cartografía del siglo XVIII..., op.cit. p.123 y ss.

12. Manzano Agugliaro, Francisco: San-Antonio-Gómez, Carlos y Manzano Agugliaro, Gil: «El levantamiento topográfico y la cartografía en el siglo XVIII: el método de la topografía eclesiástica», XVII Congreso Internacional INGEGRAF-ADM., Sevilla, 2005, pp. 1-11. 
diseño espontáneo les han llevado a ser calificados de toscos, inútiles, infantiles, por parte de quienes se han aproximado a ellos ${ }^{13}$.

No han gozado de mayor crédito los croquis insertos entre la documentación que conforma el ingente acervo documental del Catastro de Ensenada a los que vamos a dedicar la siguientes páginas.

\subsection{Qué figura tiene, poniéndola al margen}

De nuevo es la cuestión de un interrogatorio la que da origen a esta documentación figurativa. En este caso, la tercera pregunta de un total de 40 que conforman lo que se conocerán como las Respuestas Generales:

Qué territorio ocupa el término; cuánto de Levante a Poniente y de Norte a Sur, y cuánto de circunferencia, por horas y leguas; qué linderos o confrontaciones; y qué figura tiene, poniéndola al margen.

No me voy a detener en explicar el proceso de producción de esta fuente puesto que existe una abundante bibliografía acerca de este abrumador conjunto documental, sobre su origen, desarrollo y proceso de ejecución que ocupa los años centrales del siglo XVIII (1750-1754) ${ }^{14}$. Tan sólo recordaré que reunidas las personalidades correspondientes en las casas habilitadas para ello, se daba comienzo a la evacuación del interrogatorio general que abarcaba las más variadas cuestiones sobre la población catastrada. Será la tercera cuestión, referida a los límites territoriales del término, la que exija una representación de la localidad. El autor de la misma sería el propio oficial o escribiente encargado de recabar la información que les iban suministrando sus declarantes.

Entonces, ¿podemos considerar estos dibujos como la expresión de la percepción territorial del entorno por parte de la población que lo habita? Desde luego no tienen el grado de inmediatez y espontaneidad de los croquis remitidos a Tomás López, pero sin duda, los responsables de las elaboraciones de los planos contaron con las indicaciones y sugerencias de los vecinos de la localidad elegidos para participar en las operaciones. No podía ser de otra forma. Para llevar a cabo tan magna empresa se debió contar con la colaboración de los vecinos que hubieron de participar aportando información a todos los niveles, también en lo concerniente a la imagen del territorio.

13. Sólo cabe mencionar el análisis semiótico de estos dibujos realizado en la década de los 80 por el francés VAYssière, Bruno-Henri: «Cartes minimales», Cartes et figures de la Terre, París, 1980.

14. La obra más clásica sobre el catastro de Ensenada es la de Matilla Tascón, Antonio: La Única contribución y el Catastro del Marqués de la Ensenada, Madrid, 1947. Después de ella se multiplicaron los estudios sobre este conjunto documental, destacando los trabajos de Concepción Camarero Bullón quien en 2002 dirigió el magnífico estudio que se realizó con motivo de la exposición itinerante organizada por el Ministerio de Hacienda: Camarero Bullón, Concepción (dir.): El Catastro de Ensenada. Magna averiguación fiscal para alivio de los Vasallos y mejor conocimiento de los Reinos. 1749-1756, Madrid, 2002. Los capítulos incluidos en este libro junto con otros muchos artículos que versan sobre el Catastro de Ensenada se pueden consultar en la revista de la Dirección General del Catastro, CT Catastro disponible en la siguiente dirección www. catastro.meh.es. 
Sea como fuere, lo cierto es que atendiendo a las características que presentan estos croquis podemos hablar, recogiendo las palabras de Concepción Camarero Bullón, de la primera cartografía popular de las tierras de Castilla. Una cartografía que, precisamente, por su «rudeza y simplicidad», nos ofrece la oportunidad de:

Realizar un completo estudio de cómo se percibía el espacio y cómo se reflejaba en sus representaciones: la desmesura en el ancho de los cursos de agua, la desproporción con que se señalan los molinos, batanes, iglesias, castillos, la simbología utilizada para representar otros accidentes, las denominaciones utilizadas para los puntos cardinales, la orientación que se da a las representaciones, etc ${ }^{15}$.

Consideradas desde esta perspectiva, creo más que justificado su análisis junto al de los croquis remitidos al geógrafo Tomás López, a pesar de estar separadas temporalmente por varios decenios.

La petición de «poner al margen» la figura del término, al igual que ocurre con los croquis remitidos a López, fue interpretada con gran libertad. La falta de directrices o la ausencia de un modelo específico dieron lugar a representaciones muy dispares. Algunos realizaron auténticos paisajes, representaciones muy descriptivas, con una gran cantidad de detalles en lugar de las simples figuras que se solicitaban. Otros, en cambio, se limitaron a trazar de forma muy sucinta la línea de contorno. La mayoría de las representaciones son ejecutadas con la propia tinta de escritura, salvo aquellas que aparecen dibujadas con aguadas de distintos tonos (contrastan los tonos grises y azulados con los rojos, naranjas o verdes $)^{16}$.

Más allá de la definición general de dibujos, planos o croquis que venimos utilizando para referirnos a estas imágenes, han de ser consideradas ante todo como la expresión gráfica de una representación mental o imagen subjetiva del entorno. Se constituyen en vehículos de expresión de dichas representaciones cognitivas a las que difícilmente se podría acceder de otro modo. Estas imágenes mentales llevadas al papel mediante el dibujo contienen elementos idiosincráticos derivados de la subjetividad del individuo que las realiza, pero también reflejan percepciones o contenidos significantes compartidos por el grupo social en el que dicho sujeto se inserta. Es decir, el individuo participa de las representaciones mentales colectivas y esta es la clave que nos permite encontrar en las cogniciones espaciales caracteres comunes a partir de los cuales realizar agregaciones y/o generalizaciones ${ }^{17}$.

Aunque reconozcamos las particularidades perceptivas del individuo derivadas de factores tales como la edad, el sexo, la extracción social, etc., se puede afirmar que en los procesos de cognición ambiental experimentados por un grupo de individuos que comparten un mismo contexto espacial -un determinado ámbito territorial, por

15. Camarero Bullón, Concepción: «La cartografía en el Catastro de Ensenada, 1750-1756», Estudios Geográficos, Tomo LIX, n 231, 1998», p. 282.

16. Ruíz Márquez, José Luis: Almería y sus pueblos a mediados del siglo XVIII, Almería, 1981.

17. ÍÑIgueZ, Lupicinio y POL, Enric (coords.): Cognición, representación y apropiación del espacio, Barcelona, 1996. 
ejemplo- existen semejanzas subyacentes de carácter general, al menos en lo que atañe a la interpretación de determinadas realidades o fenómenos, como pueden ser la organización territorial, relaciones espaciales o la percepción del paisaje.

En este sentido, el criterio que nos permite realizar agregaciones o generalizaciones con el fin de superar el escollo de la representación individualizada, singular o particular, es el de la familiaridad y accesibilidad al territorio experimentado por los autores de los dibujos. El sentimiento de pertenencia a un lugar, de apego y arraigo -sobre todo entre los autores de los croquis enviados a López- son conceptos que entran en juego de forma poderosa a la hora de establecer valores y significados espaciales, los cuales se sitúan en la base de la percepción. Es en función de este criterio generalizador, fundamentado en la familiaridad y accesibilidad al espacio cotidiano, que los individuos de un grupo afiliado a dicho espacio construyen sus percepciones ambientales en oposición a las de aquellos que lo consideran desde la distancia o desde fuera.

El fenómeno de pertenencia, apego, apropiación simbólica e incluso el recorrido como instrumento de descubrimiento y asignación de significados, el uso y acceso cotidiano al entorno, además de contribuir a la construcción de representaciones colectivas de un grupo, sanciona las diferencias perceptivas de dicho grupo con respecto a las de aquellos otros que permanecen ajenos a dichos fenómenos.

De ahí la importancia que concedemos a estas imágenes como manifestaciones de una mirada territorial alternativa a la del poder que es a la que el historiador, tradicionalmente, ha prestado mayor atención. Si bien es cierto que la aproximación teórica y metodológica de los historiadores culturales hacia perspectivas y enfoques socio-antropológicos han permitido en los últimos años un abordaje de la problemática territorio/ religiosidad más amplio, integral y complejo ${ }^{18}$.

\section{LA DIMENSIÓN ESPACIAL DE LA RELIGIOSIDAD POPULAR}

Entre las relaciones y experiencias que el hombre establece y desarrolla en sus escenarios de vida, la religiosa es una de las más transcendentes, no sólo por el papel que desempeña en sus conciencias sino también por su implicación en la configuración/organización del territorio -también en su comprensión/interpretación-. Es decir, la experiencia religiosa configura el territorio pero también lo dota de sentido.

18. Los trabajos del antropólogo social José Antonio González Alcantud o Antonio García Benítez - este último desde la sociología-, vienen planteando desde los años 90 interesantes reflexiones sobre la manera de afrontar el binomio territorio/religiosidad. González AlCANTUD, José Antonio: «Territorio y religión popular en Andalucía Oriental», Álvarez Santaló, Carlos, Buxó i Rey, María Jesús y Rodríguez Becerra, Salvador (coords.): La religiosidad popular..., op. cit. 197-214. Ya desde una perspectiva histórica, debemos mencionar el esfuerzo por afrontar la problemática conceptual de la expresión «religiosidad popular» por parte de SÁNCHEZ LORA, José Luís: «Religiosidad popular: un concepto equívoco», en SERrano Martín, Eliseo (ed.): Muerte, religiosidad y cultura popular, siglo XIII-XVIII, Zaragoza, 1994. 
Habitualmente se alude a la dimensión temporal del fenómeno religioso cristiano en tanto que factor determinante de los distintos tiempos de la vida del hombre.

El tiempo se percibe, se mide y se data, en su corta duración de todos los días y de todos los años, que era el tiempo que interesaba a los que lo vivían, con medidas litúrgicas y nomenclaturas del santoral ${ }^{19}$.

Sin embargo, no podemos olvidarnos de su dimensión espacial. La religión cristiana, tanto en su faceta de poder institucionalizado como en lo que atañe a las prácticas y experiencias de religiosidad popular, se materializa y manifiesta a nivel espacial. Tim Unwin nos recuerda a este respecto cómo el cristianismo ha ayudado a «dar forma al paisaje europeo a través de la formalización de una organización parroquial y diocesana, así como por la creación de importantes elementos simbólicos en el paisaje» ${ }^{20}$.

Las implicaciones espaciales del fenómeno religioso es un tema harto complejo que comprende un amplio abanico de contenidos y enfoques. En este caso, como apuntaba más arriba, más que incidir en la caracterización o identificación de esas huellas tangibles materializadas en el paisaje bajo la forma de grandes edificios o manifestaciones arquitectónicas menores (ermitas, calvarios, etc.), me interesa abordar a partir de estos documentos figurativos el orden o discurso espacial (intangible pero real) vinculado a la experiencia religiosa y elaborado a partir de las relaciones de poder, estrategias de control, apropiación territorial y significación simbólica de los espacios.

Concretando, me centraré en analizar la dimensión espacial de la religiosidad popular en estos croquis o planos atendiendo a fenómenos y conceptos tales como: la problemática de la diferenciación/jerarquización espacial, asignación de significados específicos a determinados espacios, construcción de identidades colectivas y estrategias de apropiación territorial.

Para acometer la primera de las cuestiones, esto es, la de la utilización de los iconos religiosos (templos y ermitas o santuarios) en estas imágenes como instrumentos de diferenciación espacial (espacio geográfico y espacio compositivo de la representación), parto de la siguiente pregunta: ¿el modo en que aparecen representados dichos iconos, refleja o evidencia, efectivamente, una supuesta distinción entre dos formas de pensar y sentir la religión en la Edad Moderna?

Para dar respuesta a esta cuestión resulta conveniente dedicar previamente unas líneas a esclarecer lo que León C. Álvarez Santaló denominó la religión de la inteligencia y la religión de las vísceras. Con tales expresiones se refería este autor a esa supuesta antítesis que tuvo lugar en la Edad Moderna entre una religión clerical fundamentada en la reflexión, la doctrina y la capacidad de crítica y la religión

19. EgIDO, Teófanes: «Mentalidad y percepciones colectivas», Álvarez SANTALÓ, León Carlos y Cremades Grĩ̃án, Carmen María: Mentalidad e ideología en el Antiguo Régimen, II Reunión científica, Asociación Española de Historia Moderna, Murcia, 1993, p. 63.

20. Unwin, Tim: A European Geography, London, 1998, p. 59 
popular tildada de oscura, ignorante, inocente, crédula, supersticiosa y fetichista, evidenciada a partir de la proliferación de ermitas, santuarios, capillas, calvarios, cruces callejeras, y los comportamientos y actitudes religiosas que se asocian a ellos. Hablamos de supuesta antítesis en el sentido de que, como señala Santaló, a pesar del maniqueísmo en la opinión de los protagonistas, el esquema no resulta tan simple ya que: «el ámbito religioso contiene en sí mismo una ambigüedad esencial que diluye las fronteras entre lo racional y lo irracional, entre la idea y el sentimiento, el análisis y la adhesión» ${ }^{21}$.

No resulta fácil determinar el límite o la frontera entre la religión institucional u oficial y la religiosidad popular porque, como afirma Antonio Domínguez Ortiz, tal límite no existe más que para la segunda mitad del siglo XVIII, momento en el que no sólo se estableció una frontera sino que «se cavó una fosa» entre ellas.

El primer error que hay que desmontar es identificar la religión popular con la religiosidad del pueblo, de las clases inferiores de la sociedad (...). La religiosidad popular no estaba ligada a jerarquías sociales; era una manera de sentir, de vivir la religión ${ }^{22}$.

Si bien el siglo XVII significó el apoteosis de una religiosidad popular inventada, alentada e incluso dirigida desde las más altas autoridades eclesiásticas, la segunda mitad del siglo XVIII, con sus nuevos aires ilustrados, pretende desacralizar -que no descristianizar- creencias y prácticas religiosas, eso sí, no siempre con un criterio lo suficientemente fundamentado o sistemático.

Sin embargo, siglos de exaltación piadosa no pueden borrarse de las conciencias en unos pocos años ni con la palabra ni la pluma de los más vehementes ilustrados. Las huellas dejadas en el territorio por esas prácticas de religiosidad popular con las que convivieron distintas generaciones, así como los ritos y ceremonias, en definitiva, los comportamientos colectivos que llevaban aparejadas, difícilmente podían eliminarse de sus representaciones mentales -y del territorio- en tan poco lapso de tiempo. Prueba de ello lo encontramos en las representaciones que nos ocupan.

Las manifestaciones de religiosidad popular expresadas en comportamientos lúdico-festivos o en rituales de devoción -romerías, procesiones, etc.,- y asociadas a una serie de signos sagrados que aparecen diseminados en el paisaje rural tales como santuarios, ermitas, calvarios, etc., comparten el espacio compositivo en estas imágenes con la expresión religiosa por excelencia del cristianismo institucionalizado: el templo. Su coexistencia y paridad visual en estas representaciones desdibuja esa frontera entre lo racional, lo verdadero y ortodoxo y lo irracional, ingenuo, supersticioso y anacrónico.

21. Álvarez Santaló, León Carlos: «Control y Razón: la religiosidad española del siglo XVIII», Álvarez SANTALó, León Carlos: Las cofradias de Sevilla en el siglo de la crisis, Sevilla, 1999, p. 22.

22. Domínguez Ortiz, Antonio: «Iglesia institucional y religiosidad popular en la España barroca», Córdoba, Pierre y Etienvre, Jean Pierre, La fiesta, la ceremonia y el rito, Madrid, 1990, p. 10. 


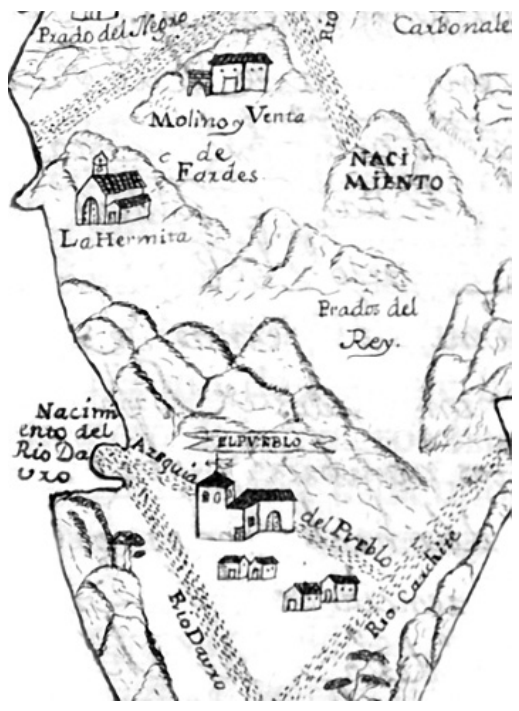

Huétor Santillán (Granada. C. de Ensenada) $)^{23}$

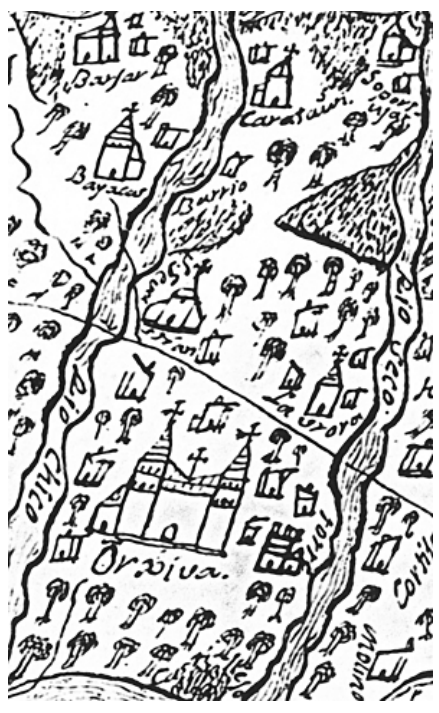

Órgiva

(Granada. Croquis remitido a T. López) $)^{24}$

Ambas dimensiones del fenómeno religioso tienen cabida en estas imágenes: tanto la dimensión más dogmática como la que se prodiga en rituales de piedad y veneración. Su conjugación a nivel espacial/compositivo es la expresión de una síntesis inevitable que tiene lugar a nivel ideológico y comportamental: la que se produce entre la fe cristiana y la devoción más exaltada o intimista, entre el dogma y el ritual.

Ahora bien, ambas devociones, aunque forman parte indisoluble del fenómeno religioso en su conjunto -alimentándose y enriqueciéndose mutuamente-, es innegable que quedan fijadas a un ámbito espacial concreto al que imprimen un significado específico. Si observamos las imágenes comprobaremos que frente a la presencia incontestable de la iglesia en ámbito urbano -entendiendo aquí por urbano el núcleo del pueblo-, las cruces, calvarios y, fundamentalmente, ermitas y santuarios aparecen en estrecha comunión con el paisaje. Estamos hablando de una dicotomía entre centro/

23. Las imágenes que se reproducen del Catastro de Ensenada correspondientes a las provincias de Granada, Málaga y Almería están tomadas del inventario de los libros del Catastro conservados en el Archivo Histórico Provincial de Granada publicado en soporte digital: Jiménez SERRANO, Bárbara y SERRANO Gutiérrez, Juan Manuel: El Catastro del Marqués de la Ensenada en el antiguo Reino de Granada, colección instrumentos de descripción número 16, Granada, Junta de Andalucía, Consejería de Cultura, 2004. En cuanto a la imagen del Catastro de Ensenada correspondiente al pueblo de Jaén, Villanueva del Arzobispo, está tomada de la siguiente publicación: LóPEz PÉREZ, María Elena: «Figuras de términos municipales de Jaén en el Catastro de Ensenada: documentación conservada en el Archivo Histórico Provincial de Jaén», Boletín del Instituto de Estudios Giennenses, nº 44 (169), 1998.

24. Las reproducciones de los croquis remitidos al geógrafo Tomás López han sido tomadas de los siguientes manuscritos ubicados en la Biblioteca Nacional de España: Granada, Ms. 7303. Sevilla: Ms. 7306. 
periferia que nos lleva a la pregunta que lanzábamos al principio ¿se establece una jerarquía espacial a partir de estos iconos religiosos? ¿una jerarquía espacial que implique diferenciaciones de rango, de legitimidad o ilegitimidad entre formas de manifestación religiosa? Insisto en negar esta idea. Más que en términos de jerarquía, rango, preeminencia o incluso de competición por el espacio de las diversas formas de vivencia religiosa, habría que afrontar esta cuestión en términos de significación espacial, o como decíamos más arriba, en términos de asignación de significados específicos.

Como veremos en el aparado siguiente, en estas comunidades locales se produce una distribución específica de los iconos religiosos en el territorio. Dicha distribución no es casual. Responde a una serie de motivos funcionales, sociales, pero también, simbólicos.

\section{TOPOGRAFÍAS RELIGIOSAS}

La fijación de un centro supone la proyección o creación de un horizonte. El caos es reducido a orden, a cosmos. La «cosmificación» de un territorio equivale a su transformación en universo ordenado y armónico, gracias a ese centro. Por lo cual, ese lugar «central» es considerado lugar sagrado ${ }^{25}$.

En las comunidades rurales la iglesia no sólo cumple con una función religiosa o cultual sino que se erige como núcleo de la vida social de la villa. Constituye el enclave en torno al cual se organiza y desarrolla la vida de la comunidad. Este fenómeno, desde un punto de vista morfológico, llevó a la construcción de un territorio articulado en función de un edificio convertido en símbolo del nuevo orden político y religioso: la iglesia. Este hito espacial acabará convirtiéndose, por tanto, en un elemento dominante del paisaje espiritual de los hombres y mujeres de la Edad Moderna, pero también de su comprensión espacial a una escala mucho mayor. Trascendiendo a un plano más abstracto, su microcosmos precisaba de un centro a partir del cual ubicarse, orientarse y estar en el mundo. Ese centro lo va a constituir la parroquia, el templo, en cuanto símbolo de lo sagrado.

En el caso de los croquis enviados a Tomás López recordemos que se trata de representaciones ejecutadas principalmente por párrocos. Sabemos que la percepción del espacio depende de múltiples factores relacionados con el sujeto, entre ellos el sexo, la edad, la categoría profesional, pero también el uso y acceso a dichos espacios por parte de los individuos.

Cada hombre se mueve en un universo personal, organizado concéntricamente en torno a él. La esfera más inmediata es el medio de su actuación habitual, del que posee una información personal y directa [...]. Lo más alejado estaría constituido por aquellos territorios de los que no posee más que referencias vagas ${ }^{26}$.

25. Maldonado, Luis: Introducción a la religiosidad popular, Santander, 1985, p. 156.

26. CAPEl SÁEz, Horacio: Las nuevas geografias, Barcelona, 1991, p. 62 
No es de extrañar, por tanto, que en los mapas cognitivos de estos curas, sacristanes o capellanes, la iglesia se erija como referente fundamental de sus escenarios de vida por lo que ésta significa: centro de trabajo, residencia, modo de vida, ejercicio de poder, identidad personal.

Pero también, y de forma fundamental, inciden en dicha percepción de la realidad que les rodea los valores culturales, los paradigmas mentales de estos sujetos. Para el individuo que habita un espacio, éste nunca es homogéneo, uniforme o neutro sino que contiene porciones cualitativamente diferentes. Esas diferencias en la cualidad del espacio se establecen en función de distintos criterios. Para el sujeto religioso el criterio fundamental lo establece la dicotomía sagrado/profano. Para el individuo que no posee creencias religiosas, los criterios que establecen distinciones espaciales vendrán determinados por las preferencias, los recuerdos, los miedos, las emociones, etc. -aunque éstas no están ausentes, hay que decirlo, en las percepciones del hombre religioso-.

Los autores de los croquis enviados a Tomás López y los elaborados por los miembros de las audiencias encargados del catastro, los primeros por su condición de párrocos y los segundos por estar insertos en un contexto social fuertemente sacralizado, tendrán una visión del espacio condicionada por lo sagrado. Los hitos espaciales de carácter religioso tales como templos, ermitas o calvarios, además de objetos de referencia espacial, constituyen hierofanías (manifestación de lo sagrado). Son los puntos de anclaje de su universo, necesarios para escapar del caos, de la imprecisión.

La revelación del espacio sagrado tiene un valor existencial para el hombre religioso: nada puede comenzar, hacerse, sin una orientación previa y toda orientación implica la adquisición de un punto fijo. Por esta razón el hombre religioso se ha esforzado por establecerse en el centro del mundo. Para vivir en el mundo hay que fundarlo, y ningún mundo puede nacer en el caos de la homogeneidad y de la relatividad del espacio profano $^{27}$.

La dimensión territorial de lo sagrado se va a manifestar no sólo en el establecimiento de un centro fijo en torno al cual organizar el espacio físico y espiritual, sino que se explicita también en la propia orientación de los planos. Muchos de ellos sitúan el este en la parte superior de la representación, a veces indicado con el dibujo de un sol. Asumimos la orientación simbólica de las plantas de los templos cristianos como una convención arquitectónica: el ábside en el que se sitúa el altar se dirige hacia oriente, dirección que se identifica con el nacimiento del sol, con la vida, etc. El extremo occidental, en cambio, se asocia con la muerte, el pecado; de ahí que el tema decorativo principal de la entrada de las iglesias sea el Juicio Final. Sin embargo, nos resulta más difícil aceptar una orientación en los mapas que no esté dirigida al norte.

27. Eliade, Mircea: Lo sagrado y lo profano, Barcelona, 2005, p. 21. 


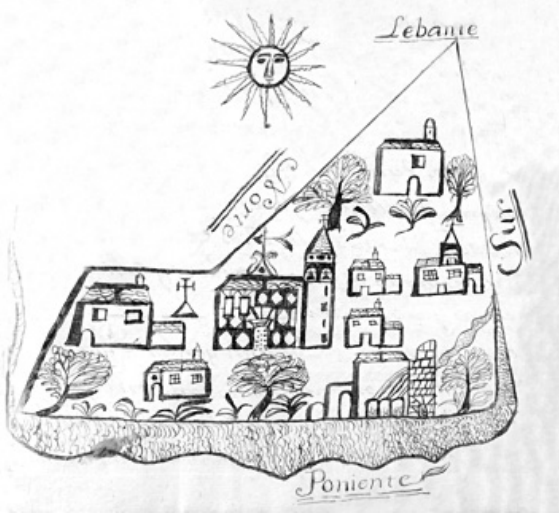

Gójar (Granada. Catastro de Ensenada)

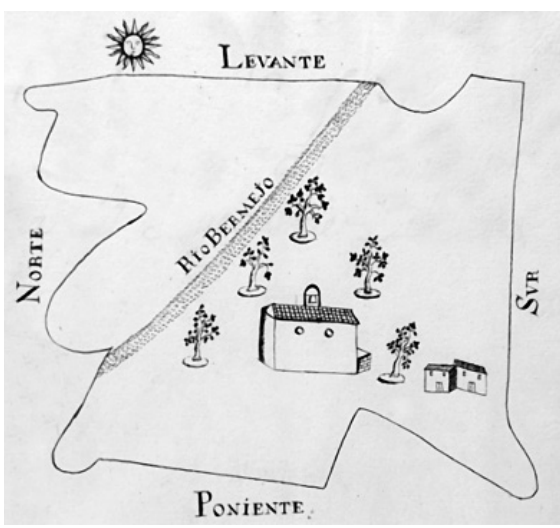

Calicasas (Granada. Catastro de Ensenada)

Y es que, por encima de los convencionalismos geográficos se imponen los símbolos, el imperio de la ideología, en este caso, religiosa.

Como centro aglutinador de espacios y grupos, el templo adquiere en estos dibujos el rango de símbolo de la vida en comunidad. Considerado como uno de los edificios más representativos de la comunidad rural, en torno él se organizaban buena parte de las actividades cotidianas de estos hombres y mujeres del siglo XVIII.

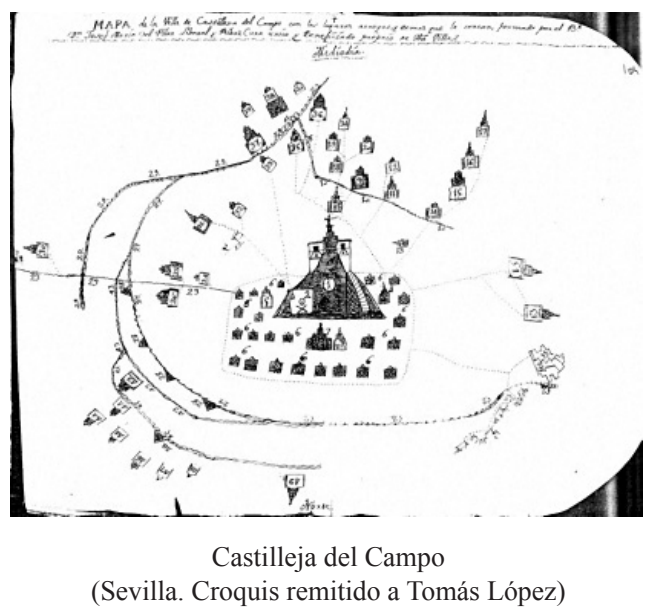

En la gran mayoría de los dibujos, la población por la que se interroga es representada en el centro geométrico de la composición mediante el dibujo de una iglesia rodeada de viviendas que aparecen a modo de satélites. Este esquema de representación, muy repetido, viene a subrayar el carácter de aquella como elemento organizador del espacio, esto es, como nodo o eje en torno al cual se estructura el espacio de la villa o lugar. 
Arnheim, desde la perspectiva de la composición visual, afirma que el centro como el lugar hacia el que todo converge y del que emana el poder decisivo, puede conceder la primacía por su mera posición a una zona u objeto que de no ser así carecería de relieve visual ${ }^{28}$. La función plástica de esos componentes del espacio urbano que se disponen alrededor del icono eclesiástico, más que aportar información sobre la morfología urbana (ya que en la mayoría de los casos se reducen a minúsculas figuras geométricas indeterminadas) sería la de enfatizar el carácter de la iglesia o parroquia -en su doble dimensión de edificio físico e institución- como centro de la comunidad local.

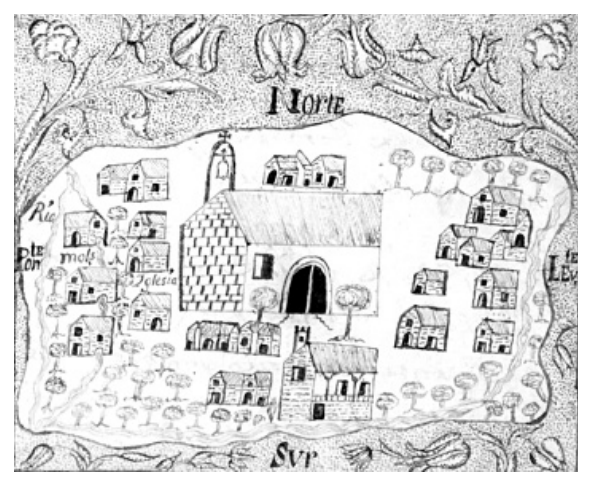

Jubrique (Málaga. Catastro de Ensenada)

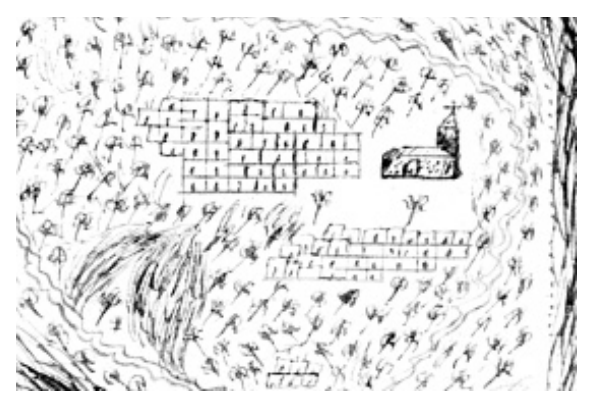

Olula de Castro (Almería. Catastro de Ensenada)

Otras estrategias compositivas para acentuar el concepto de comunidad con una identidad común son: las orientaciones forzadas de los demás elementos de la composición con el fin de hacerlos converger hacia ese centro aglutinador o la uniformidad con la que éstos se representan frente a la singularidad con la que se dibuja el hito religioso.

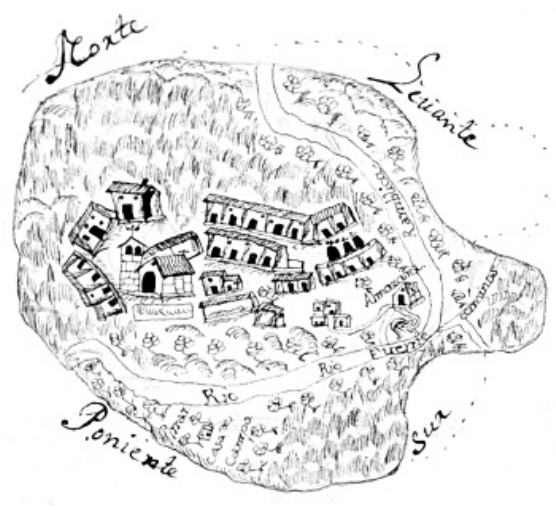

Líjar (Almería. Catastro de Ensenada)

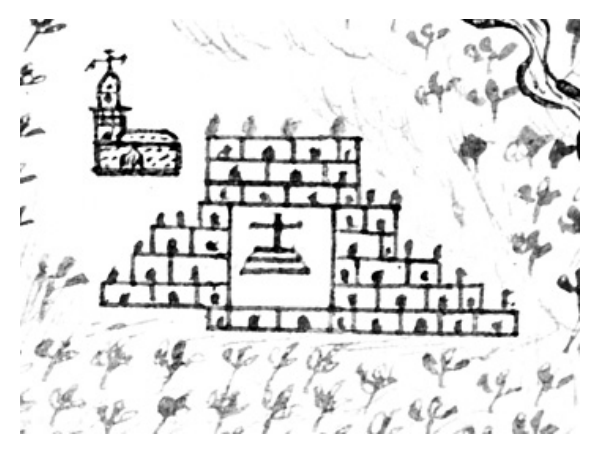

Bentarique (Almería. Catastro de Ensenada)

28. ARnHeIM, Rudolf: El poder del centro, Madrid, 1988. 
En muchos otros casos, la correspondencia entre ese centro y la comunidad social llega a tal grado de identificación que el pueblo se llega a representar únicamente mediante el icono de la iglesia. Desde esta perspectiva se entienden muchas de las representaciones que a modo de sinécdoque visual recurren a la parte por el todo, a emplear el icono de la iglesia como forma de representación del conjunto de la villa o lugar.

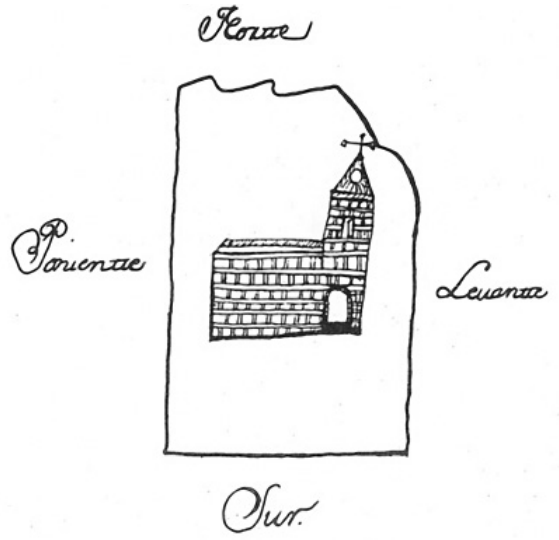

Villanueva del Arzobispo (Jaén. C. de Ensenada)

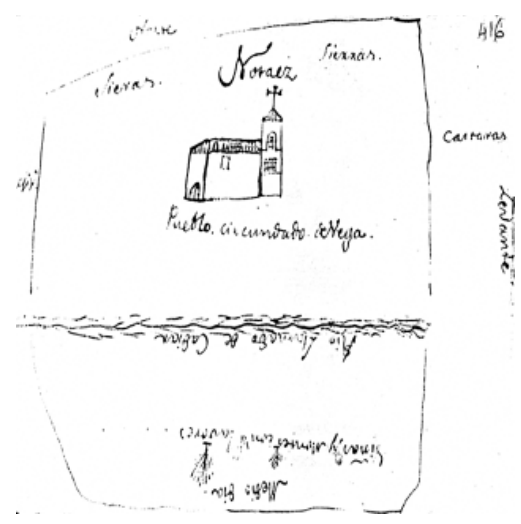

Notáez (Granada. Croquis remitido a T. López)

La comunidad rural organizada socialmente mediante vínculos de distinta naturaleza (de autoridad/sumisión, pertenencia/exclusión, paternalismo/deferencia, asistencia, solidaridad, etc.), es también una comunidad jerárquica, con una autoridad visible, una cabeza que dirige los movimientos de los demás miembros. No extraña que sea esa cabeza visible la que acabe representando el conjunto de la comunidad en sus mapas cognitivos.

Trascendiendo el particularismo de estos hitos espaciales y su significación simbólica o ideológica, estas estrategias de representación vienen a acentuar el concepto de unidad y cohesión que se pretende transmitir como seña de identidad por parte de estas comunidades:

La vida de una comunidad, especialmente si es rural, implica fundamentalmente organización de la convivencia y simbiosis con el medio geográfico. Estos dos aspectos actúan como potentes generadores de cultura. No podemos hablar de comunidad si no detectamos en los vecinos un específico sentido de pertenencia a un grupo, la vivencia de un «nosotros» homogéneo, es decir, un sentimiento solidario ${ }^{29}$.

Resumiendo, el templo ocupa el centro urbano, el centro en las representaciones mentales del espacio percibido por sus habitantes y el centro compositivo en el intento de exteriorización de lo que venimos llamando mapas cognitivos. Un centro como

29. Maldonado, Luis: Introducción..., op.cit., p. 159. 
espacio (geográfico y compositivo) que confiere un valor específico a los elementos ubicados en él, ¿o es al contrario? En realidad es un juego recíproco de transmisión de significados entre el valor intrínseco del centro geográfico/centro geométrico de la composición y los valores con los que se dota el templo religioso/icono. Orden, unidad, cohesión, incluso regulación, legitimación y control son los conceptos que se vinculan y se vehiculan con y a través de dichos centros.

Dentro de ese orden territorial que establece la topografía sagrada, las ermitas, cruces y calvarios dominan los espacios circundantes al núcleo de población mostrándose como hitos en perfecta comunión con el paisaje.

Nos desplazamos, pues, del centro a la periferia, de lo urbano a lo paisajístico. Y lo que es más importante, nos desplazamos también en altura, esto es, de un plano a ras del suelo a otro más elevado - con las implicaciones simbólicas que esto conlleva y que comentaremos a continuación-.

En palabras de Yolanda Olmedo, las ermitas, también concebidas como santuarios, «son pequeños templos que encuentran su mayor asiento al abrigo de la naturaleza, al ser éste el lugar más idóneo para crear un espacio dedicado a la meditación ${ }^{30}$. Se instalan, pues, en medio de parajes de excelencia paisajística, en lugares que invitan a la contemplación y al deleite sensorial como vías para conseguir la comunión con lo espiritual. En ellos, la experimentación de lo natural es la clave para la aproximación a lo sobrenatural.

Los «logoi spermatikoi» pétreamente cristalizados que nos traducen a un lenguaje más explícito esa vivencia, ese mensaje sagrado, hierofánico, transmitido al hombre de modo silencioso, inarticulado, por el monte, el valle, la gruta, el arroyo, la fuente, el árbol, el bosque... ${ }^{31}$

La naturaleza propicia el encuentro con lo sagrado. En la experiencia religiosa ya no participan solamente el individuo y la divinidad sino que en este diálogo de sensaciones y vivencias entra en juego, como mediador, el paisaje.

Es esta, sin embargo, una argumentación relativamente moderna. La valoración sensitiva del paisaje sólo es posible cuando se rescata del exilio al universo de los sentidos. La concepción de la naturaleza/paisaje como lugar de meditación, oración y encuentro con la divinidad se hace factible a partir de la elaboración conceptual de las categorías de lo bello y lo sublime que se desarrollan en el siglo XVIII. Junto a la progresiva aparición de estas categorías estéticas también resulta fundamental el discurso filosófico de tinte naturalista que va adquiriendo fuerza a lo largo de esta centuria y que pone el acento en la revelación divina a través del mundo natural. Dios como fuerza inteligible se hace presente en el orden natural. En este sentido, la interacción del hombre con la naturaleza supone su relación con la materia y con el ser físico de los objetos, pero también, con la divinidad que se hace presente en sus criaturas ${ }^{32}$.

30. Olmedo SÁnchez, Yolanda: Manifestaciones artísticas.... op. cit. p. 30.

31. Maldonado, Luis: Introducción..., op.cit., p. 149.

32. Calafate, Pedro: O conceito de natureza no discurso iluminista, Lisboa, 1991. 
Es a partir del siglo XVIII que se percibe el paisaje aislado, recogido o recóndito como lugar de encuentro con la divinidad; como espacio que propicia el diálogo, la comunicación con lo sagrado. Estas condiciones ideales se materializan no sólo en lugares elevados sino también en grutas y barrancos. Sin olvidar los cursos de agua. A todo el simbolismo del paisaje más íntimo se le suman las múltiples connotaciones y valores espirituales del agua: el agua como sustancia purificadora, vivificadora, incluso como fuente de vida.

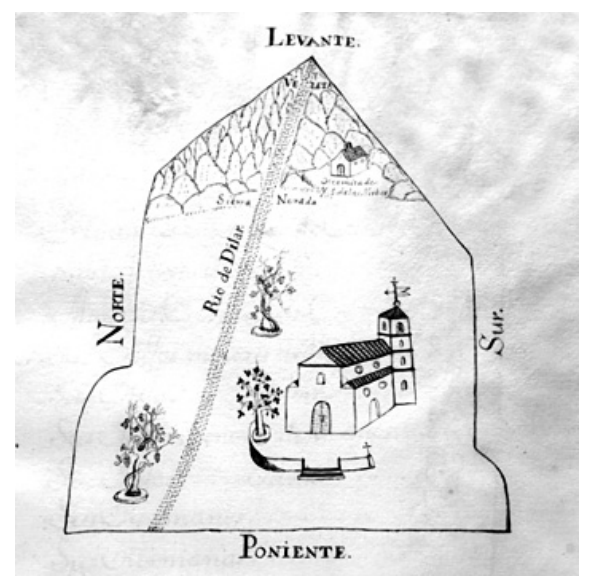

Dílar (Granada. Catastro de Ensenada)

La argumentación que sí tiene, en cambio, unas profundas raíces en nuestra cultura occidental y cristiana, es aquella que vincula la montaña con lo sagrado (recordemos el monte Olimpo, el Parnaso o el Sinaí). Me refiero al valor espiritual, ascético y místico que se le atribuye a la ascensión a la montaña como viaje metafórico. Constituye un itinerario espiritual que conduce al encuentro con lo divino, lo que dota a este accidente geográfico -en su defecto a la colina o elevación del terreno-, o más exactamente a su cima, de una fuerte carga simbólica.

La altitud y la verticalidad [...] son generalmente cualificadas positivamente. De tal modo que a la altitud corresponden conceptos de trascendencia y a la ascensión de progreso y crecimiento. En lo alto se encierran signos de lo bueno y ligero, de lo que vence el peso, de lo celeste; lo espiritual asciende; en cambio, la materia pesa y la vida ha de luchar contra tal peso. La elevación es, pues, una cualidad y la cima su logro, la victoria sobre los obstáculos materiales mediante un esfuerzo, su recompensa moral. Todo ello sacraliza la montaña y su ascenso ${ }^{33}$.

33. Martínez de Pisón, Eduardo: «Valores escondidos de los paisajes. Cualidades ocultas de la ascensión a la montaña», Martínez de Pisón, Eduardo y Ortega Cantero, Nicolás (eds.): Los valores del paisaje, Madrid, 2009, p. 23. 
De modo que si el centro otorga al objeto una significación determinada -orden, unidad, estabilidad, cohesión, control, equilibro--, la periferia, donde el paisaje natural se muestra de forma más explícita, proporciona igualmente otros valores fundamentales: espiritualidad, comunicación con lo divino, crecimiento interior.

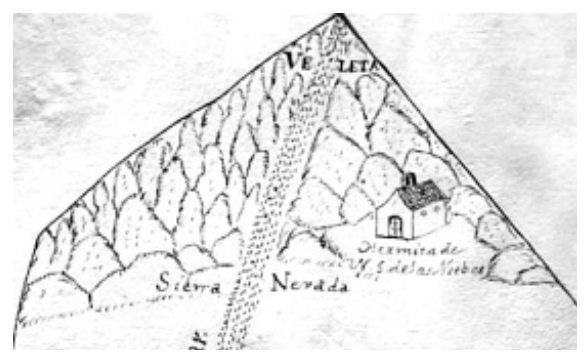

Dílar (Granada. Catastro de Ensenada)

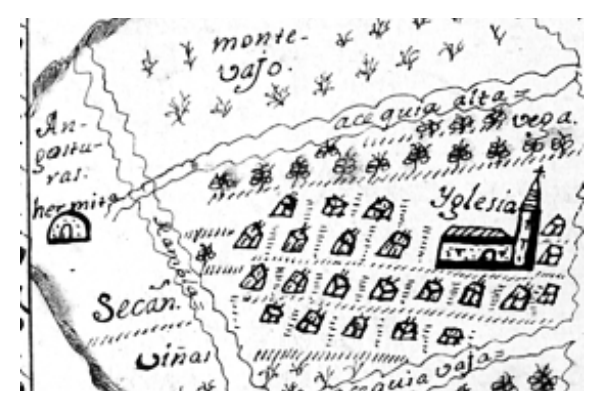

Cherín (Almería. Catastro de Ensenada)

Las ermitas y santuarios actúan también como células de conexión entre el pueblo y sus parajes circundantes, un fenómeno de implicaciones geográficas. Concebidas como punto final de un camino en el que se pretende emular el sufrimiento experimentado por Jesús en su ascenso al Gólgota, las ermitas y santuarios se convierten en centros de peregrinación y, por tanto, de enlace entre el habitante de la villa y el paisaje por el que ha de transitar para llegar a su meta mística. Como apunta Luis Maldonado, «la marcha deviene entonces en símbolo: símbolo de esfuerzo, de trabajo, de victoria». No es extraño, entonces, encontrar asociadas a las ermitas, los calvarios, estación final de cualquier Vía Crucis.

En no pocas imágenes vamos a ver representados estos calvarios en lo alto de cerros, montes o colinas; lugares elevados próximos a la población, auténticos montes calvario que convierten a la villa en una especie de Nueva Jerusalén. Estos itinerarios sagrados recogidos en los croquis construyen, por tanto, espacios «simbólicos, ilusorios y ficticios» a través de cuyo recorrido se le ofrece al pueblo la posibilidad de vivir la Pasión de $\mathrm{Cristo}^{34}$. En conexión con esta interpretación, resultan especialmente interesantes las palabras que José Miguel Muñoz Jiménez dedica a estos espacios simbólicos:

Estamos así, cuando todo peñón cercano a la población se hace Gólgota y lugar de prácticas piadosas, ante un claro ejemplo de creación, por medio de requerimientos religiosos, de una geografía imaginaria, que se superpone a la geografía rea ${ }^{35}$.

34. MuÑoz JimÉneZ, José Miguel: «Sobre la «Jerusalén Restaurada»: Los calvarios barrocos en España», Archivo Español de Arte, tomo 69, n² 274, 1996. Págs. 157-170.

35. MuÑoz JimÉNEZ, José Miguel: «Los santuarios rurales en España: paisaje y paraje, (la ordenación sagrada del territorio)», Campos Fernández de Sevilla, Francisco Javier (dir.): Religiosidad popular en España, Volumen II, Madrid, 1997, p. 313. 
A la topografía física se incorporan las huellas de una topografía religiosa, testimonio de un tiempo de exaltación espiritual como lo fue el Barroco, cuyos signos y significados siguen estando presentes en el imaginario e imaginería colectiva de la sociedad andaluza de finales del siglo XVIII.

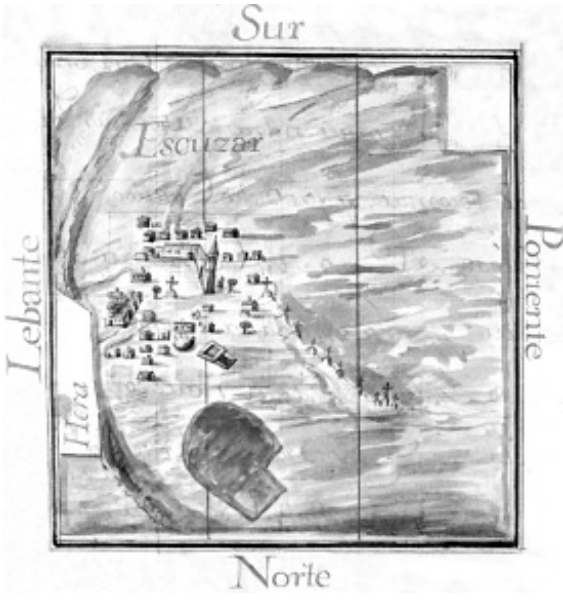

Escúzar (Granada. Catastro de Ensenada)

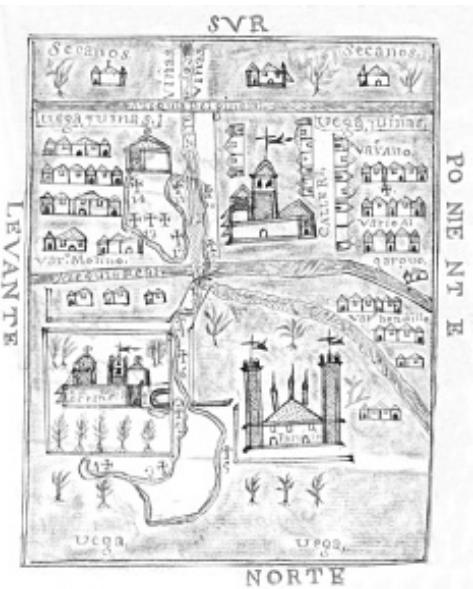

La Zubia (Granada. Catastro de Ensenada)

Para terminar, falta aún por tratar un último aspecto de aquellos que decíamos constituían el discurso espacial que estas imágenes proyectan. Junto al fenómeno de la diferenciación espacial y asignación de significados específicos espaciales, a la construcción de identidades colectivas, nos encontramos con las estrategias de apropiación territorial. En este último punto, los santuarios, ermitas y calvarios van a desempeñar un papel esencial. Además de lugares de culto y centros de sociabilidad, si se quiere marginales $-\mathrm{y}$ precisamente por ello-, esta arquitectura religiosa menor va a jugar un importante papel en las estrategias de apropiación del espacio.

La presencia de una hierofanía, además de sacralizar el territorio en el que se ubica y su área circundante, lo humaniza. El paisaje agreste, alejado y extraño sufre un proceso de apropiación por parte de la comunidad rural a la que pertenece. Se individualiza y reconoce como lugar, como centro de significado. Es considerado una prolongación del espacio urbano, o si se quiere, habitado. Suponen una estrategia de apropiación del paisaje circundante por parte de la villa. Las ermitas y santuarios son concebidos, por tanto, como hitos que sancionan y consagran los límites del término. A modo de tentáculos invisibles estos hitos se introducen en el paisaje humanizándolo, sacralizándolo $\mathrm{y}$, en última instancia, extendiendo el radio de influencia de la entidad poblacional a la periferia, involucrando al territorio que lo circunda dentro de un mismo sistema. 


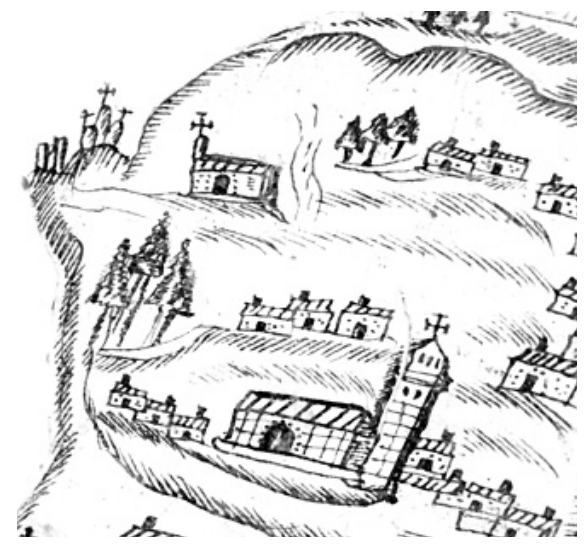

Somontín (Almería. Catastro de Ensenada)

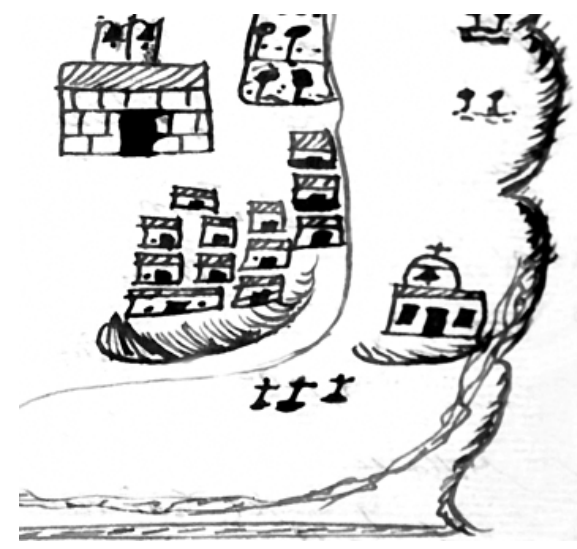

Urrácal (Almería. Catastro de Ensenada)

Frente a esa religión de la inteligencia que ocupa el centro de sus núcleos urbanos, de sus representaciones mentales y sus composiciones gráficas, la religión de las vísceras posee sus propios espacios con sus significados específicos. La religión institucional y la popular, aunque se funden en las representaciones mentales del entorno -pues ambas forman parte de la experiencia de lo sagrado- dibujan, en cambio, una topografía ordenada en la que cada una de ellas se fija a un lugar al que confieren un uso, un valor y un significado específicos. Como complemento al orden, la armonía, la unidad, la autoridad, que representa el icono eclesiástico, estas otras manifestaciones de la espiritualidad popular se sitúan en las entrañas del paisaje, más simbólico que nunca. Sus huellas se imprimen en la periferia y los márgenes de sus territorios, como periféricas y marginales son las prácticas de una religiosidad popular constantemente sometida al ojo vigilante del poder.

La convivencia con los signos sagrados que jalonan sus lugares cotidianos, la incuestionable presencia física e ideológica de la Iglesia como institución de poder y, en definitiva, la atmósfera de sacralidad que impregna aún -a estas alturas del llamado siglo de la razón- el quehacer diario de la población rural andaluza, se conjugan para dibujar en la conciencia espacial de los individuos una geografía donde tienen cabida no sólo las montañas, ríos, bosques, vegas, molinos, cortijos... sino también el templo, la ermita, la cruz y el calvario. Y no como meros elementos anecdóticos sino como referencias inevitables en sus esquemas de organización espacial como consecuencia de la significación que adquieren en sus representaciones mentales.

Se nos ofrece, por tanto, un paisaje de connotaciones económicas, político-administrativas, pero también simbólicas e ideológicas. Y es que la percepción del entorno es la de un espacio de múltiples dimensiones acorde con las distintas experiencias y relaciones que el hombre establece con y en su medio. 